\title{
Sobre a dispersão de Lutzomyia Intermedia (Diptera, Psychodidae)
}

\author{
Mario B. Aragẫo \\ Lais Clark Lima *
}

Utilizando um mapa de dominios morfoclimáticos e um de vegetação, foram estudadas as áreas de dispersão da espécie e obtidas as seguintes conclusões:

1 - Lutzomyia intermedia é um flebótomo que ocorre nas florestas que apresentam o seu máximo de desenvolvimento nas encostas umidas, mas, que ocupam também áreas de relevo pouco movimentadas ou planas.

2. No Brasil, essas encostas pertencem às serras do Mar e da Mantiqueira e, no noroeste da Argentina, situam-se na Cordilheira dos Andes.

3. É provável que a espécie exista nas serras florestadas do interior do nordeste brasileiro.

Um congresso internacional de geografia, realizado em 1956 no Rio de Janeiro, estimulou alguns estudos sobre a distribuiçâo de vetores de doenças por regiōes geográficas e, também. a correlação dessa distribuição com elementos climáticos (Aragão, 1956; Aragão \& Dias, 1956). Apesar desse método ter sido utilizado no monumental atlas de Rodenwaldt (1952) não encontrou muitos adeptos. A maioria dos autores continuou a utilizar a distribuiçâo por município, estado e país.

Recentemente. um de nós (Aragĩo, 1987) trabalhan. do no Projeto RADAMBRASIL apresentou. num congresso realizado $\mathrm{cm}$ 1976, um trabalho mostrado como os mapas tcmáticos daquele projeto, podian auxiliar no estudo da distribuição de algumas doenças.

Num exame. feito mais por curiosidade, dos mapas do "American Sand Flies" de Martins, Williams \& Falcão (1978). notou-sc que a distribuiçào da Lutzomyia intermedia, no leste do Brasil. superpunha a área do domínio mor. foclimático dos Mares de Morros, de Ab' Sáber (1970) (Figura 1) e, por esse motivo, resolvemos estudar o assunto.

O próprio mapa do "American Sand Flies" mostra que a correlação não é com a topografid característica desse domínio morfoclimático. Já o mapa da vegetação da América do Sul de llueck (1972) se revela muito mais adequado alo estudo.

* Escola Nacional de Saúde Públi. ca, 21041 Rio de Janeiro, RJ. * * Centro de Pesquisas René Ra. chou, Caixa Postal 1743, 30000 Belo Horizonte, $M G$. 


\section{FIGURA 2}

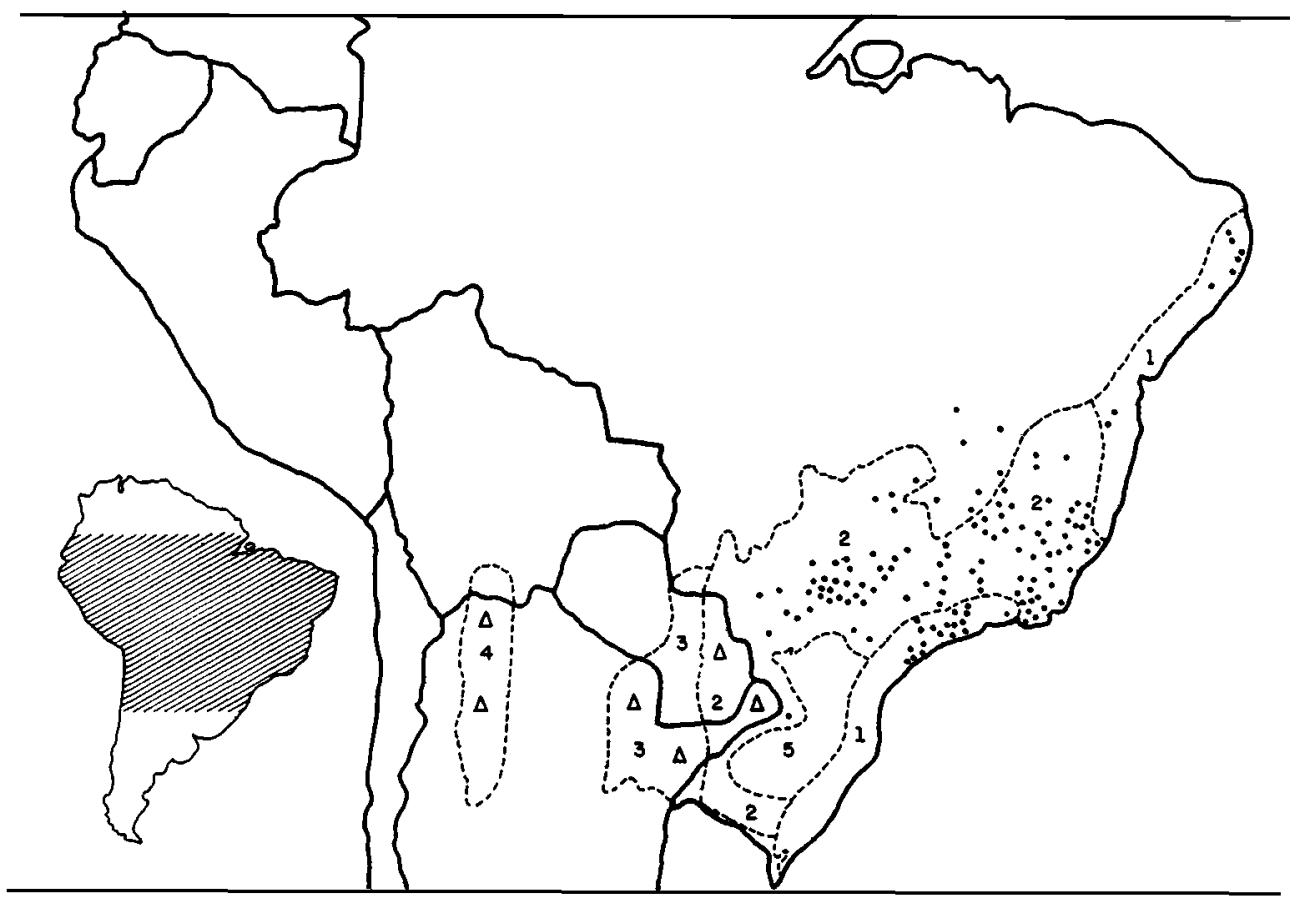

- Limite de países

...... Limites de áreas florestais

. - Localidade onde foi assinalada Lutzomyia intermedia

$\Delta$ - Províncias do Paraguai e da Argentina onde ocorreu L. intermedia Áreas florestais:

1 - Mata pluvial costeira do Brasil.

2 - Matas subtropicais do leste e do sul do Brasil

3 - Matas do chaco e áreas marginais

4 - Matas tucumano-bolivianas (Regiōes das matas das encostas orientais dos Andes)

5 - Matas de araucaria do sul do Brasil

\section{MATERIAL E MÉTODOS}

No mapa da figura 2 a distribuição da $L$. intermedia é a dada por pais, estado e município por Martins, Williams \& Falcão con algumas dúvidas esclarecidas por Forattini (1973). Devido à dificuldade de encontrar nos mapas correntes as localidades da Argentina e do Paraguai, nesses pai. ses foram plotadas apenas as províncias onde a espécie ocor. re. 
O dados de vegetação são, basicamente, de Hueck com alguns acréscimos de Rizzini (1979) e mais algumas fontes que serão mencionadas oportunamente.

Com base nas informações disponiveis sobre a flora das diversas áreas, o que se vai procurar é o que existe de geral, nos diversos tipos particulares de vegetação onde esse flebótomo ocorre.

\section{RESULTADOS E COMENTÁRIOS}

No mapa da figura 1 vê-se que do Nordeste até o estado de São Paulo, a L. intermedia é encontrada no mar de morros que era coberto pela "mata pluvial costeira do Brasil" e pelas "matas subtropicais do leste e do sul do Brasil" de Hueck (ver figura 2). Na terminologia de Rizzini são dois setores da Floresta A tlântica". A floresta pluvial montana, que cobre ou cobria as encostas das serras do Mar e da Mantiqueira e a floresta pluvial baixo montana, que se expandia do litoral dos estados do Espírito Santo e Rio de Janeiro, por áreas contínuas em parte dos estados de Minas Gerais e de São Paulo e em manchas e galerias no Planalto Central.

A floresta pluvial montana é a expressão mais pujante e mais rica em espécies da Floresta Atlântica. Já a floresta pluvial baixo montana é menos desenvolvida e com menor número de espécies mas, nas áreas mais úmidas, principalmente nas grotas, se apresenta como uma típica floresta montana.

As localidades assinaladas ao norte da legenda $2 \mathrm{da} \mathrm{fi}$. gura 2, estão todas na bacia do rio Paraná onde, nas matas ciliares, predominam espécies da Floresta Atlântica.

Do lado do Paraguai e do nordeste da Argentina, a floresta é uma extensão da brasileira. Segundo Hueck "quase toda a região montanhosa do leste do Paraguai é coberta por matas subtropicais: da mesma forma existe mata sub. tropical na Argentina, em Missiones e Corrientes".

Rambo (1951), o grande estudioso da vegetação do Rio Grande do Sul, apoiado em Cabrera, diz que "a selva sul-brasileira higrófila encontra seu limite sul extremo na foz do Rio da Prata". E o que Hueck chama de "matas do Chaco e áreas marginais" (legenda 3 da figura 2). Essa mesma idéia é esposada por Rizzini com base na lista de espé. cies publicada por Martinez-Croveto.

Também muito significativa, uma vez que trata-se de plantas que dependem da floresta, é a conclusĩo de Pabst (1951) em relação às orquídeas. Diz ele: "Fitogeografica. mente Santa Catarina (. . .) pertence ainda ao grupo floral característico do Paraná, São Paulo. Rio de Janeiro. sul de Mato Grosso, leste do Paraguai e nordeste argentino". 
No noroeste da Argentina, Províncias de Jujuy e Tucuman, a L. intermedia ocorre na Região das Matas Tucumano-bolivianas (legenda 4 da figura 2). que são as florestas que cobrem as primeiras encostas dos Andes. Os autores desconhecem a área, mas, as fotografias publicadas por Hueck mostram uma topografia semelhante à dos mares de morros do sudeste brasileiro.

A figura 2 mostra a ausencia da espécie na legenda 5. região das matas de araucária do sul do Brasil, assunto que será examinado a seguir.

\section{FIGURA 1}

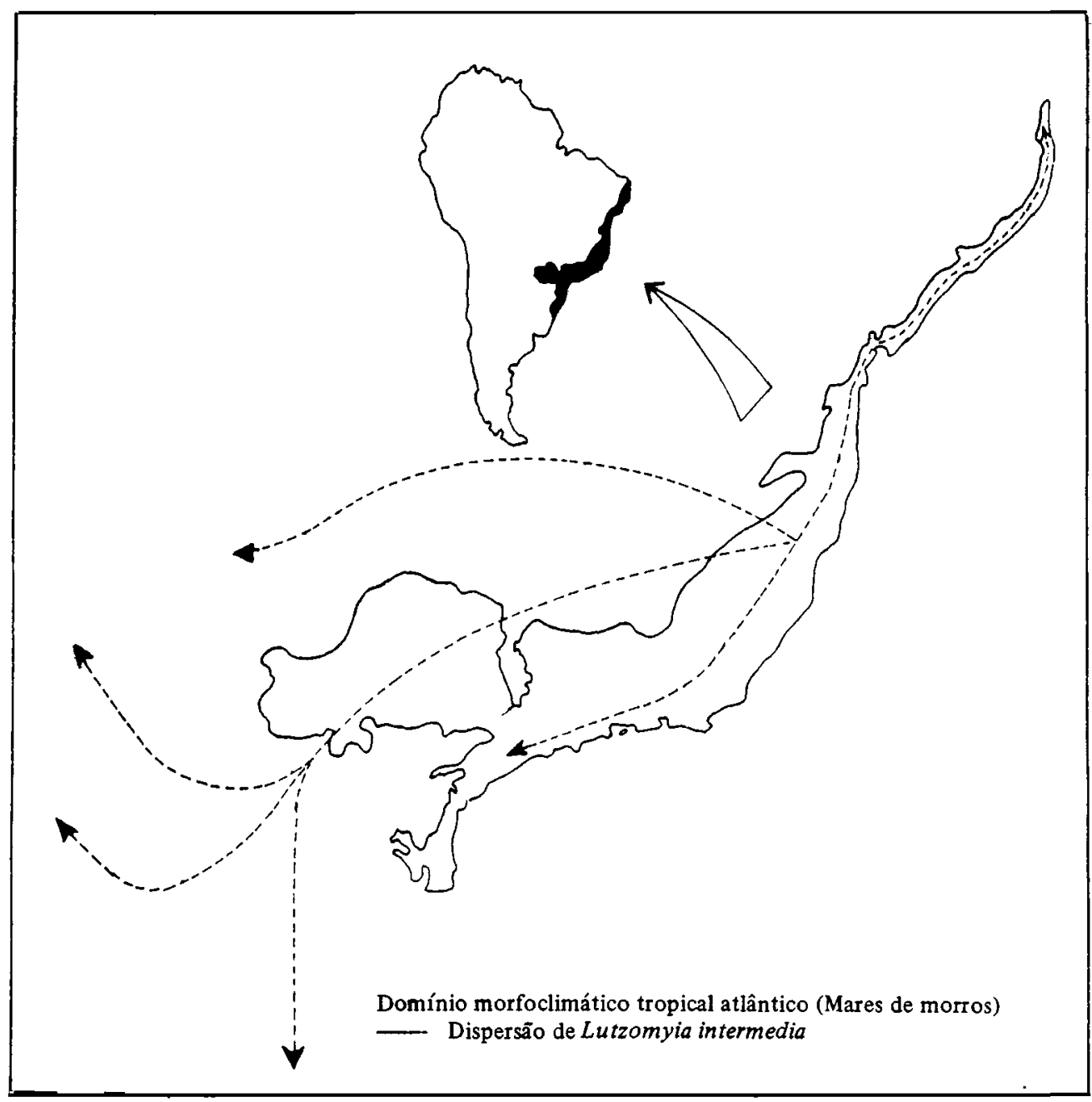


Os pinheirais à medida que vão envelhecen do vão sendo invadidos por espécies da Floresta Atlântica e quando muito idosos, são muito mais florestas latifoliadas do que pinhais. Aqui, entretanto, devem ser levados em conta dois fatores. Um, muito bem descrito por Klein (1960), de que o pinhal avança sobre as áreas de campo. Assim sendo, a periferia do pinhal é completamente dominada pela Araucaria. Outro de que, pelo menos nos estados do Rio de Janeiro e de São Paulo, a $L$. intermedia é uma espécie da periferia da mata (Lima, 1986). Sendo assim, a espécie deve encontrar dificuldade para prosperar no interior dos pinhais idosos, onde predominam as espécies da Floresta Atlântica.

Todos esses fatos induzem à conclusão de que a I. intermedia é uma espécie das florestas de encostas e de suas extensões. Entretanto, ela não está assinalada nas diversas florestas das serras existentes no nordeste brasileiro. Assunto que precisa ser examinado.

Ducke (1959) estudando a vegetação dessas serras observou que as matas têm afinidade com as da Serra do Mar, embora sejam menos ricas em espécies.

Aproveitando a excelente monografia das bromeliáceas de Reitz (1983) anotamos as espécies que ocorrem na Floresta Atlântica e nas serras do Nordeste. São ao todo oito, 4 Tillandsia, 3 Vriesea e 1 Aechmea. Isso significa que para essas plantas epifitas, os dois tipos de florestas apresentam condições semelhantes. Aliás, a semelhança entre as condições climáticas dessas áreas, situadas em zonas de circulação atmosférica distintas, já havia sido demonstrada por Aragão (1961).

\section{CONCLUSÕES}

A $L$. intermedia é uma espécie das florestas tropicais e subtropicais das encostas e de suas extensões. Essas encostas situam-se nas serras do Mar e da Mantiqueira, e nos Andes.

Pela face leste do continente é a Floresta Atlântica, com a floresta montana e a floresta baixo montana e suas extensões, sejam elas manchas, capões ou matas ciliares.

Pelo lado andino são as matas tucumano bolivianas, do noroeste argentino, que cobrem os primeiros contrafortes dos Andes.

Conclui-se também que é provável a existência da cspécie nas serras florestadas do interior do nordeste brasileiro. 
The dispersion of Lutzomyia in termedia (Diptera, Psychodidae)

Using vegetation and morphoclimactic domain maps the areas of dispersion of Lutzomyia intermedia were studied and the following conclusions were obtained:

1. L. intermedia is a sandfly of the forests which have their maximum growth at the humid slopes although these forests can also be found in plains and areas with low hills.

2. In Brazil, these slopes are found at the Serras do Mar and Mantiqueira and in Argentina ath the Andes Mountains in the northwest of the country.

3. This species probably occurs also in the forested mountainous areas of the northeastern region of Brazil.

\section{REFERÊNCIAS BIBLIOGRÄFICAS}

AB' SÁBER, A. N. Províncias geológicas e domínios morfoclimátiticos no Brasil. Geomorfologia, S. Puulo, 20: 1-26, 1970.

ARAGĀO, M. B. Aspectos climáticos do problema bromélia-malária. Rev. Bras. Malar. D. Trop., 8:621-31, 1956.

ARAC, ĀO, M. B. Sobri a vegetaçăo de zonas úmidas do Brasil. Rev. Brasil. Biol., $21: 317-24,1961$.

ARAGĀO, M. B. Enctumias rurais na Folha SA. 22 Belém, do Projeto RADAlt. XII Congresso dat Sociedade Brasiteira de Medicina Tropicili. Brekim. 1976. Cod. Saride Pribl., Rio de Janeiro. im priblicuciar.

ARAGÃO. M. B. \& DIAS, E. Aspectos climáticos da doença de Chagas. Rev. Bros. Molor. D. Trop. 8:633-41, 1956.

DUCKE, A. J studos botánicos no Ceuri. An. Acal. Bres. Ct. 31: $211-308.1959$.

JORATTINI, O. P. Entomologia medica, 49 volume. Sijo Paulo, lidgard Blücher L.tdat. \& liditura da Univervidade de Săo Paulo, 1973.

HULCK, K. As florcstas da América do Sul. Tradução de Hans Reichardt. Sĩo Paulo, Liditora Polígono S. A. \& Editora da Universidude de Brasília, 1972.

Kl.I.IN, R. M. O aspecto dinámico do pinheiro brasileiro. Sellowia. Itajaí, SC, 12:17-44, 1960.

LIMA, L. C. Ruralìą̧̃o da Lutzomyia intermedia, um provável caso de prí-idaptação. Rev. Saúde publ., S. Paulo, 20:102-4, 1986.

MARTINS, A. V. WILLJAMS, P. \&l:ALCĀO, A. L. American sand flies. Rio de Janciro, RJ, Academia Brasileira de Ciências, 1978.

PABST, (i. l. J. Contribuiçāo para o conlecimento das orquídeas de Santa Catarina e sua dispersão geográfica. An. Bot. Herb. "Barbosa Rodrigues', I tajaí, SC, 3: 41-53, 1951. 
RAMBO, B. A. imigraçāo da selva higrófila no Rio Grande do Sul. An. Bot. Herb. "Barbosa Rodrigues", I tajaí, SC, 3: 55-91, 1951.

REITZ, R. Bromeliáceas e a malária-bromélia endèmica. I tajaí, SC, Herbário "Barbosa Rodrigues", 1983.

RIZZINI, C. T. Tratado de fitogeografia do Brasil, $2{ }^{\circ}$ volume. São Paulo, "Hucitec" Ltda. \& Editora da Universidade de São Paulo, 1979.

RODENWALDT, E., Ed. World-atlas of epidemic diseases. Hamburg, Falk-Verlag, 1952. 